\title{
FATORES QUE INFLUENCIAM O ENDIVIDAMENTO DOS ESTADOS BRASILEIROS
}

\author{
FACTORS THAT INFLUENCE THE DEBIT OF BRAZILIAN STATES
}

\author{
GILMAR RIBEIRO DE MELLO \\ Doutor em Controladoria e Contabilidade pela \\ Universidade de São Paulo \\ Professor Adj unto da Universidade Estadual do Oeste do Paraná - Unioeste, \\ Campus de Francisco Beltrão. \\ Francisco Beltrão/ PR - Brasil \\ E-mail: gilmarribeirodemello@gmail.com
}

\author{
VALMOR SLOMSKI \\ Doutor em Controladoria e Contabilidade pela \\ Universidade de São Paulo \\ Professor do Programa de Pós-graduação da Faculdade de Economia \\ Administração e Contabilidade da Universidade de São Paulo - \\ São Paulo/ SP, Brasil
E-mail: valmor@usp.br
}

\begin{abstract}
RESUMO
O endividamento dos Estados Brasileirosestá diretamente ligado à capacidade de investimentos no desenvolvimento do bem-estar social, porém, alguns governantes usaram essa forma de obtenção de recursos de forma irracional, deixando seu Estado com dívidas de difícil gestão. Muitas vezes a falta de informações é fator decisivo para tal ocorrência, assim, este trabalho tem por objetivo identificar os fatores que influenciam o endividamento dos Estados Brasileiros, considerando os aspectos relacionados à estrutura de receitas e despesas. Para cumprir esse objetivo foram identificados na revisão bibliográfica os principais fatores, relacionados com receitas e despesas, que poderiam contribuir para tal explicação. A população é composta pelos 26 Estados Brasileiros, o período pesquisado é de 2000 a 2005 e a ferramenta estatística utilizada é a regressão com dados em painel. Os resultados demonstraram que os fatores que mais influenciam o endividamento são aqueles relacionados às receitas de transferências, a receita per capita e a cobertura corrente total (essa influência ocorre de forma negativa), além disso, há influência do próprio endividamento do período anterior, que impacta de forma positiva.
\end{abstract}

Palavras-chave: endividamento; dívida pública; estados brasileiros.

\section{ABSTRACT}

The indebtedness of Brazilian States is directly connected with the investment capacity in social welfare development. However, some governors have used this way of obtaining resources irrationally, charging their State with debts that are hard to manage. The lack of information often represents a decisive factor for this occurrence. Hence, this study aims to identify the factors that influence the indebtedness of Brazilian States, considering the aspects related to the revenue and expense structure. To comply with this objective, a bibliographic review was carried out to identify the main factors, related to revenues and expenses, which could contribute to this explanation. The population includes the 26 Brazilian States, the research period ranges from 2000 to 2005 and the statistical tool used is regression with panel data. The results demonstrated that the factors that most influence indebtedness are related to revenues from transfers; per capita revenue and total current coverage (this influence is negative). Moreover, another factor of influence is the indebtedness from the previous period, which exerts a positive impact.

Key words: indebtedness; public debt; Brazilian states. 


\section{INTRODUÇÃO}

A dívida líquida do setor público no Brasil, em dezembro de 1994 , era $28,1 \%$ do Produto Interno Bruto - PIB, correspondente a R\$ 192 bilhões, passando, em junho de 2002, para R\$ 709 bilhões $(55,9 \% \text { do PIB })^{1}$. Esse aumento deu origem a preocupações relativas às perspectivas futuras do endividamento público, gerando críticas à condução da política econômica nos últimos anos, centrada principalmente no ônus que o serviço da dívida traz para o orçamento governamental, numa situação de juros altos, restringindo a capacidade do governo de empregar recursos em itens mais relacionados ao bem-estar social.

De acordo com o Banco Central, essa mesma dívida, em maio de 2007, já ultrapassou R\$ 1,096 bilhão, representando $44,7 \%$ do PIB, sendo que, desse total, em torno de $30 \%$ é dívida dos Estados Brasileiros.

As causas do crescimento da dívida nos últimos anos, a possibilidade da continuidade ou recorrência desses fatores no futuro próximo, a sustentabilidade da dívida, são indagações que têm aparecido com freqüência na literatura de finanças públicas, na imprensa, no parlamento, ou mesmo entre o público leigo. E não é raro que tais indagações exprimam uma visão simplista das origens e dos males associados ao endividamento público.

O endividamento dos Estados e Municípios Brasileiros teve a primeira crise, conforme Silva e Sousa (2002, p. 3), após a moratória da dívida externa mexicana em 1982, marcada pela redução do fluxo de capital externo para o país. Os Estados Brasileiros deixaram de honrar seus compromissos externos, obrigando o Governo Federal a pagar as dívidas estaduais e municipais, visto que o Tesouro Nacional era garantidor dessas operações.

As renegociações das dívidas estaduais e municipais ocorridas nas últimas décadas evidenciaram o relaxamento desses entes na condução fiscal responsável de suas finanças, resultando no comportamento explosivo de suas dívidas. Essas renegociações criaram, por um lado, um problema de risco moral, na medida que incentivaram um endividamento excessivo no presente, apoiado na crença de um socorro financeiro no futuro. Por outro, elas contribuíram para o progressivo aperfeiçoamento dos mecanismos de controle das finanças estaduais. Por fim, como complemento dessas políticas para promover o ajuste fiscal, foi publicada, em 2000, a Lei de Responsabilidade Fiscal - LRF.

A LRF estabelece normas de finanças públicas voltadas à responsabilidade na gestão fiscal, em que um dos objetivos, dentre os inúmeros nela definidos, é controlar o avanço do endividamento com a fixação de regras e limites. Assim, fixa limites para algumas despesas, como com pessoal, para dívida pública, determina que sejam criadas metas para controlar receitas e despesas, foca as ações dos governantes na transparência e equilíbrio das contas públicas.

Nesse contexto, este artigo tem como questão de pesquisa: os aspectos relacionados à estrutura de receitas e despesas influenciam o endividamento dos Estados Brasileiros?

No intuito de responder essa pergunta, o objetivo da pesquisa é identificar os fatores que influenciam o endividamento dos Estados Brasileiros, considerando os aspectos relacionados à estrutura de receitas e despesas.

Isso se justifica em função de que, a obtenção de informações quanto aos principais

$1 \quad$ Banco Central do Brasil (2002). 
fatores que influenciam as variações do endividamento dos estados brasileiros, possibilitará aos gestores públicos estaduais melhorarem sua administração, prevendo as variações e facilitando a decisão de um maior ou menor endividamento.

Assim, a hipótese orientadora é que os aspectos relacionados à estrutura de receitas influenciam para a redução do endividamento, enquanto que os aspectos relacionados à estrutura de despesas influenciam para o aumento do endividamento.

\section{REVISÃO BIBLIOGRÁFICA}

O endividamento público, foco deste trabalho, deriva necessariamente da circunstância de o ente público realizar despesas superiores às suas receitas. Esse descompasso entre receitas e despesas é possível apenas em face de uma de duas condições: ou, no caso da União, há a emissão de dinheiro para fazer frente às despesas, ou, no caso de qualquer dos entes, há a concessão de crédito por alguém. O endividamento é uma das formas de financiamento desse descompasso (Pereira, 2002).

Para Versiani (2003. p. 8), nos últimos anos, três elementos tiveram impacto significativo no aumento do endividamento do Governo Federal: "os acordos de refinanciamento de Estados e Municípios, o reconhecimento e contabilização dos passivos contingentes e o programa de fortalecimento dos bancos federais."

Segundo Rigolon e Giambiagi (1999), entre 1989 e 1998 a dívida líquida dos Estados e Municípios passaram de 5,8\% para 14,4\% do Produto Interno Bruto - PIB. Isso acorreu apesar de a Constituição de 1988 ter alterado a repartição da receita tributária em favor dos Estados e Municípios.

A tendência ao desequilíbrio nas finanças públicas estaduais e municipais parece decorrer tanto de demandas e pressões legítimas da sociedade por uma expansão de gastos públicos, tornadas mais aparentes após o processo de redemocratização, quanto de um possível comportamento estratégico do poder público, nessas unidades (Versiani, 2003).

Esse último ponto, segundo Rigolon e Giambiagi (1999), se refere ao fato de que os governos estaduais e municipais, percebendo sua capacidade de influenciar politicamente as decisões na esfera federal, podem adotar uma postura de desinteresse em relação à consecução de um equilíbrio entre receitas e despesas, confiando numa intervenção salvadora do governo central.

Esse comportamento poderia ter sido reforçado pela ocorrência de várias intervenções federais dessa natureza, especialmente a partir de 1985, como a renegociação da dívida externa dos Estados e a renegociação das dívidas dos Estados com as instituições federais.

Quanto aos passivos contingentes, o governo federal realizou operações, na última década, com o objetivo de assumir dívidas latentes, ou seja, compromissos assumidos no passado, de diversas formas, pela União, mas que não tinham sido contabilizados como dívidas efetivas, por exemplo: o déficit do Fundo de Compensação de Variações Salariais (com o propósito de subsidiar os mutuários do Sistema Financeiro de Habitação) e os débitos e obrigações de entidades extintas ou privatizadas, como o Lloyd Brasileiro, a Rede Ferroviária Federal, a Superintendência da Marinha Mercante - SUNAMAM, o Instituto do Açúcar e do 
Álcool etc (Versiani, 2003).

O Programa de Fortalecimento das Instituições Federais (PROEF) foi estabelecido em 2001, com o objetivo de permitir aos bancos federais se adequarem aos padrões de capitalização e de previsão de riscos de crédito estabelecidos pelo Acordo de Basiléia (definiu diversas normas prudências quanto à relação entre elementos do ativo e do passivo, quanto à definiçãa de classificação de risco, aos níveis adequados de provisão etc).

O endividamento dos Estados e Municípios Brasileiros tem muitas explicações, uma delas é citada por Lopreato (2000, p. 9) como sendo decorrente da liberdade dos governadores usarem a articulação financeira entre o Tesouro, os bancos estaduais e as empresas na alavancagem de recursos, onde os bancos estaduais concentraram elevada parcela dos empréstimos nos próprios Estados, compensando a redução do crédito dos agentes federais, além de comprometerem parte de seus ativos no carregamento dos títulos da dívida mobiliária, sobretudo nos principais Estados responsáveis pela expansão das dívidas mobiliárias como fonte de captação de recursos.

Outro fator preponderante no aumento do endividamento, foi a falta de definição de condições sustentáveis para o total das dívidas estaduais e a rolagem da dívida não negociada, com base nas altas taxas de juros em vigor no Plano Real, alimentando o componente financeiro do endividamento e contribuindo para a deterioração patrimonial das empresas e bancos estaduais. Na verdade, a renegociação parcial da dívida e as medidas de controle do acesso a novos financiamentos pouco serviram para frear o endividamento (Lopreato, 2000, p. 15).

Outros pontos, como a dependência de recursos transferidos pelo Governo Federal, a estrutura de gastos desses governos e a importância econômica do Estado são citados por Silva e Sousa (2002, p. 20) como fatores relevantes para explicar a evolução da dívida.

Com a LRF começando a ser cumprida em 2001, os Estados Brasileiros passaram a melhor controlar o grau de endividamento, e aqueles Estados com o endividamento considerado acima do teto estabelecido pela Resolução 40/2001, do Senado Federal, começaram a adotar medidas para tal adequação. Pesquisas feitas por Mello, Slomski e Corrar (2005), Mello et al (2006) e Mello e Slomski (2006) demonstram essa preocupação e mostram a redução do grau de endividamento da maioria dos Estados considerados endividados.

Atualmente, quando se fala na identificação do endividamento dos Estados Brasileiros, o indicador mais utilizado é o previsto na LRF, como sendo a relação entre a dívida consolidada líquida e a receita corrente líquida ( $\mathrm{DCL} / \mathrm{RCL})$, com limite de dívida de duas vezes a receita corrente líquida.

Ao tratar-se dos possíveis fatores de receitas e despesas que podem influenciar no endividamento dos Estados Brasileiros, Mello e Slomski (2006), após identificá-los através de análise fatorial, sugerem:

a) Indicadores de estrutura de receita.

- Proporção de receitas que o Estado recebe do governo federal: relação entre as transferências federais e as receitas de fontes próprias (TF / RFP);

- Participação da receita tributária: relação entre as receitas tributárias e a receita total (RTrib. / RT); 
- Participação das receitas de transferência: relação entre as receitas de transferências e a receita total (RTransf. / RT);

- Participação do FPE: relação entre o fundo de participação dos estados e a receita total (FPE / RT);

- Participação do ICMS: relação entre o imposto sobre circulação de mercadorias e serviços e a receita total (ICMS / RT);

- Receitas per capita: relação entre as receitas próprias e a população (RP / População);

- Financiamento das dívidas de custeio: relação entre a as dívidas de custeio e as despesas correntes (RT / DC);

- Cobertura corrente total: relação entre as receitas tributárias, menos as despesas correntes, e as receitas tributárias (RTrib. - DCor.) / RTrib.);

- Cobertura corrente própria: relação entre as receitas tributárias com ICMS e as despesas correntes ((RTrib.+ ICMS) / DCor.).

b) Indicadores de estrutura de despesa.

- Participação da variação da dívida na receita total: relação entre a variação da dívida líquida no tempo t e t-1 e a receita total (VDP / RT);

- Parcela de ativos disponível a curto prazo: relação entre o ativo total, menos 0 ativo permanente, e o ativo total ((AT - AP) / AT);

- Participação de despesas de custeio: relação entre as despesas de custeio e as receitas orçamentárias líquidas (DC / ROL);

- Participação das despesas com pessoal: relação entre as despesas com pessoal e a receita corrente líquida (DP / $\mathrm{RCL})$;

- Utilização nominal das receitas de capital: relação entre a receita de capital, menos a despesa de capital, e a receita de capital ((RC - DC) / RC).

Além dos indicadores acima, serão considerados os sugeridos por Silva e Sousa (2002), que já discutiram esse assunto e demonstraram que os aspectos relacionados com às fontes de financiamentos e à estrutura de gastos dos governos são fatores que influenciam 0 endividamento. Os indicadores considerados por elas, já excluídos os relacionados a gasto com pessoal e com a arrecadação do ICMS, pois eles também são sugeridos por Mello e Slomski (2006), são:

- Grau de dependência de recursos transferidos pela União: utiliza-se a relação entre as transferências correntes e a receita corrente líquida.

- Gastos com Investimento: consiste na relação da rubrica investimento das despesas de capital e a receita corrente líquida;

Uma vez definidos os indicadores, cabe destacar o detalhamento da metodologia da pesquisa e dos procedimentos estatísticos empregados para auxiliar a obtenção de 


\section{METODOLOGIA}

Para a concretização deste estudo, foi utilizada como técnica de trabalho a pesquisa empíco-analítica, que segundo Martins (2002, p. 34) "são abordagens que apresentam em comum a utilização de técnicas de coleta, tratamento e análise de dados marcadamente quantitativas. Privilegiam estudos práticos. Suas propostas têm caráter técnico, restaurador e incrementalista".

Os dados utilizados para calcular os indicadores foram obtidos nos relatórios contábeis e financeiros do banco de dados da Secretaria do Tesouro Nacional. Os indicadores foram calculados para todos os Estados Brasileiros, exceto o Distrito Federal, no período de 2000 a 2005. A exclusão do Distrito Federal é justificada pela estrutura de seus gastos/receitas, que diferem dos Estados analisados, assim, essas peculiaridades poderiam causar distorções nos resultados.

As variáveis foram assim definidas:

- Variável Dependente (Y) - Grau de endividamento dos Estados (medido pela relação Dívida Consolidada Líquida e Receita Corrente Líquida - DCL/ $\mathrm{RCL}$ ), identificado como GEE.

- Variáveis Independentes $(\mathbf{X})$ - Indicadores $\left(X_{1}, \ldots, X_{p}\right)$, especificados no Quadro 1.

Quadro 1 - Resumo das Variáveis Independentes

\begin{tabular}{|l|c|c|}
\hline \multicolumn{1}{|c|}{ Significado } & Fórmula* & $\begin{array}{c}\text { Variáveis } \\
\text { Independentes }\end{array}$ \\
\hline Receitas recebidas governo federal & TF / RFP & RGF \\
\hline Receita Tributária & RTrib. / RT & RTrib \\
\hline Receitas de Transferência & RTransf. / RT & RTransf \\
\hline Participação no Fundo de Participação dos Estados & $\mathrm{FPE} / \mathrm{RT}$ & $\mathrm{FPE}$ \\
\hline Participação do ICMS & $\mathrm{ICMS} / \mathrm{RT}$ & $\mathrm{ICMS}$ \\
\hline Receitas per capita & $\mathrm{RP} / \mathrm{Pop}$. & $\mathrm{RPC}$ \\
\hline Financiamento das dívidas de custeio & $\mathrm{RT} / \mathrm{DC}$ & $\mathrm{DC}$ \\
\hline Cobertura corrente total & (RTrib. - DCor.) / RTrib. & $\mathrm{CCT}$ \\
\hline Cobertura corrente própria & ((RTrib. ICMS) - DCor & $\mathrm{CCP}$ \\
\hline Participação da variação da dívida na receita total & $\mathrm{VDP} / \mathrm{RT}$ & $\mathrm{VD}$ \\
\hline Parcela de ativos disponível a curto prazo & $($ (AT - AP) / AT & $\mathrm{ACP}$ \\
\hline Participação de despesas de custeio & $\mathrm{DC} / \mathrm{ROL}$ & DespCust \\
\hline Participação das despesas com pessoal & $\mathrm{DP} / \mathrm{RCL}$ & $\mathrm{DespPes}$ \\
\hline Utilização nominal das receitas de capital & (RC - DC) / RC & RCap \\
\hline Grau de dependência de recursos transferidos pela União & $\mathrm{TC} / \mathrm{RCL}$ & $\mathrm{TC}$ \\
\hline Gastos com Investimento & $\mathrm{DC} / \mathrm{RCL}$ & $\mathrm{Gl}$ \\
\hline
\end{tabular}

* As fórmulas e respectivas siglas estão explicadas na página 4. 
Com relação à técnica estatística a ser utilizada, adotou-se a regressão com Dados em Painel, pois de acordo com Gujarati (2006) nos dados em painel, a mesma unidade de corte transversal (uma família, uma empresa, um estado) é acompanhada ao longo do tempo. Em síntese, os dados em painel têm uma dimensão espacial e outra temporal.

A técnica de regressão com dados em painel se adequa perfeitamente ao tipo de amostra utilizada, pois trata-se de 26 Estados, que são os cross-section (corte transversal) e os dados dos indicadores, distribuídos nos anos de 2000 a 2005, que formam a série temporal.

A análise de painel permite relaxar e contrastar os supostos que estão implícitos na análise de corte transversal. Há dois aspectos fundamentais: controlar a heterogeneidade inobservável (explorar a variação temporal), e a utilização das defasagens como variáveis instrumentais em modelos dinâmicos.

\section{RESULTADOS DA PESQUISA}

Os procedimentos estatísticos, quando se utiliza dados em painel, são chamados de estimação, e isso diz respeito à variação ou não dos coeficientes da regressão.

Assim, o primeiro procedimento de estimação é executar o painel chamado "Modelo Comum", que considera todos os coeficientes constantes ao longo do tempo e entre os indivíduos, e segundo Gujarati (2006) tem como característica servir como base de comparação com os modelos de efeitos fixos e efeito aleatório, com o objetivo de escolher aquele que melhor se adequa à amostra pesquisada, e pode ser representado pela seguinte função:

$$
\mathrm{Y}_{\mathrm{it}}=B_{1}+B_{2} \mathrm{X}_{2 \mathrm{it}}+B_{3} \mathrm{X}_{3 \mathrm{it}}+B_{\mathrm{n}} \mathrm{X}_{\mathrm{nit}}+\mu_{\mathrm{it}}
$$

Na função 1, o $Y_{\text {it }}$ representa a variável dependente de cada unidade de seção cruzada i no tempo t, o $B_{1}$ é o coeficiente linear (intercepto), o $B_{2}$ é o coeficiente angular da variável independente $X_{2 i t}$ de cada unidade de seção cruzada i no tempo $t, 0 B_{3}$ é o coeficiente angular da variável independente $X_{3 i t}$ de cada unidade de seção cruzada i no tempo t e $0 \mu_{\text {it }}$ é o termo de erro de seção cruzada i no tempo t.

O procedimento acima, foi executado considerando todas as variáveis independentes demonstradas no Quadro 1, porém, em virtude da ocorrência de correlação entre algumas variáveis e que os coeficientes angulares dessas variáveis não são significativamente diferentes de zero, as variáveis RGF, RTrib, FPE, ICMS, DC, CCP, VD, ACP, DespCust, DespPes, RCap, TC e GI foram excluídas da regressão.

Após isso, o modelo comum de dados em painel foi estimado com apenas as variáveis RTRANSF, RPC e CCT, conforme Tabela 1. 


\section{Tabela 1 - Resultado do Painel pelo Modelo Comum}

\begin{tabular}{|c|c|c|c|c|}
\hline \multicolumn{5}{|c|}{$\begin{array}{l}\text { Variável Dependente: Grau de Endividamento dos Estados - GEE } \\
\text { Método: Pooled Least Squares } \\
\text { Período: } 20002005 \\
\text { Observações Incluídas: } 6 \\
\text { Número de cross-sections usado: } 26 \\
\text { Total de observações do painel: } 155 \\
\text { White Heteroskedasticity-Consistent Standard Errors \& Covariance }\end{array}$} \\
\hline Variáveis & Coeficientes & Erro padrão & Estatística t & Prob. \\
\hline C-Constante & 2,70494 & 0,24763 & 10,92317 & 0,00000 \\
\hline RTRANSF? & $-3,26496$ & 0,48185 & $-6,77586$ & 0,00000 \\
\hline RPC? & $-0,00035$ & 0,00019 & $-1,88170$ & 0,06180 \\
\hline CCT? & $-0,18173$ & 0,08811 & $-2,06267$ & 0,04086 \\
\hline $\mathrm{R}^{2}$ & 0,35759 & \multirow{5}{*}{\multicolumn{2}{|c|}{$\begin{array}{l}\text { Média da var. dep. } \\
\text { Desvio-padrão da var. dep. } \\
\text { Soma do quad. dos resid. } \\
\text { Estatística de Durbin-Watson }\end{array}$}} & 1,36424 \\
\hline $\mathrm{R}^{2}$ aiustado & 0,34482 & & & 0,81436 \\
\hline S.E. da regressão & 0,65917 & & & 65,61015 \\
\hline Estatística F & 28,01700 & & & 0,28641 \\
\hline Prob(Estatística F) & 0,00184 & & & \\
\hline
\end{tabular}

Fonte: Elaboração própria a partir dos dados gerados pelo software.

A Tabela 1 inicialmente nos mostra qual é a variável dependente (GEE), o método de estimação utilizado, o período em que os dados foram coletados, o número de cosssections usado (26 estados), o número total de observações do painel (155) e que o painel foi estimado considerando a consistência do erro padrão e covariância pela heterocedasticidade de White.

Na sequiência verificam-se as variáveis incluídas no modelo, seus coeficientes, erro padrão, estatística t e sua probabilidade. Nesse momento o que se deve destacar é que o coeficiente angular da variável RPC não é significativamente diferente de zero (Prob. $=0,06180$ > nível de significância de 0,05 ) e que o $\mathrm{R}^{2}$ ajustado (poder de explicação do modelo) é de apenas 0,34482 (34,5\%). Esses destaques nos levam a suspeitar que o modelo comum não seja o mais apropriado, mas é necessário estimar os outros modelos para fins comparativos.

\subsection{MODELO DE EFEITOS FIXOS}

A estimação dos efeitos fixos depende das premissas que se faz a respeito do intercepto, dos coeficientes angulares e do termo de erros. Neste trabalho o "Modelo Fixo" adotado, considera que os coeficientes angulares são constantes, mas o intercepto varia entre os indivíduos, que segundo Gujarati (2006) pode ser representado pela seguinte função.

$$
\mathrm{Y}_{\mathrm{it}}=B_{1 \mathrm{i}}+B_{2} \mathrm{X}_{2 \mathrm{it}}+B_{3} \mathrm{X}_{3 \mathrm{it}}+B_{\mathrm{n}} \mathrm{X}_{\mathrm{nit}}+\mu_{\mathrm{it}}
$$

Embora o intercepto $\left(B_{1 \mathrm{i}}\right)$ possa definir entre indivíduos (pela técnica das variáveis binárias de intercepto diferencial), cada coeficiente angular individual não se altera ao longo do tempo.

Esse modelo, segundo Wooldridge (2006) tem como método de estimação os mínimos 
quadrados ordinários - MQO, o qual, aplicado nos desvios das variáveis em relação a média, elimina todos os efeitos que não variam com o tempo. E, segundo Silva e Cruz Jr. (2004), para que o MQO seja válido, os erros devem ser homocedásticos e não-correlacionados.

0 resultado da estimação desse modelo está descrito na Tabela 2, a seguir.

Tabela 2 - Resultado do Painel pelo Modelo Fixo

\begin{tabular}{|c|c|c|c|c|}
\hline \multirow{2}{*}{\multicolumn{5}{|c|}{ Variável Dependente: Grau de Endividamento dos Estados - GEE }} \\
\hline & & & & \\
\hline \multicolumn{5}{|c|}{ Método: Pooled Least Squares } \\
\hline \multicolumn{5}{|c|}{ Período: 20002005} \\
\hline \multicolumn{5}{|c|}{ Observações Incluídas: 6} \\
\hline \multicolumn{5}{|c|}{ Número de cross-sections usado: 26} \\
\hline \multicolumn{5}{|c|}{ Total de observações do painel: 155} \\
\hline \multicolumn{5}{|c|}{ White Heteroskedasticity-Consistent Standard Errors \& Covariance } \\
\hline Variáveis & Coeficientes & Erro padrão & Estatística t & Prob. \\
\hline RTRANSF? & $-1,17293$ & 0,31223 & $-3,75659$ & 0,00026 \\
\hline RPC? & $-0,00040$ & 0,00001 & $-3,98448$ & 0,00011 \\
\hline ССТ? & $-0,15964$ & 0,02802 & $-5,69694$ & 0,00008 \\
\hline \multicolumn{5}{|l|}{ Efeitos Fixos } \\
\hline _AC--C & 1,28116 & & _PB--C & 1,78430 \\
\hline AL--C & 2,86287 & & _PE--C & 1,52429 \\
\hline _AM--C & 1,25661 & & _PI--C & 2,12047 \\
\hline AP--C & 0,68161 & & _PR--C & 1,74026 \\
\hline _BA--C & 2,03884 & & _RJ--C & 2,61436 \\
\hline CE--C & 1,45213 & & RN--C & 1,18112 \\
\hline _ES--C & 1,49124 & & _RO--C & 1,79882 \\
\hline _GO--C & 3,07136 & & _RR--C & 0,98820 \\
\hline _MA--C & 2,64403 & & _RS--C & 3,26308 \\
\hline _MG-C & 2,67017 & & _SC--C & 2,18337 \\
\hline _MS--C & 3,32714 & & _SE--C & 1,32151 \\
\hline _MT--C & 2,34457 & & _SP--C & 2,70969 \\
\hline _PA--C & 1,17163 & & _TO--C & 1,00141 \\
\hline $\mathrm{R}^{2}$ & 0,92884 & Média da var. & & 1,36424 \\
\hline $\mathrm{R}^{2}$ aiustado & 0,91303 & Desvio-padrão & & 0,81436 \\
\hline S.E. da regressão & 0,24017 & Soma do quad. & & 7,26767 \\
\hline Estatística F & 822,32242 & Estatística de D & in-Watson & 1,27591 \\
\hline Prob(Estatística F) & 0,00000 & & & \\
\hline
\end{tabular}

Fonte: Elaboração própria a partir dos dados gerados pelo software.

Analisando os resultados do painel pelo modelo fixo, verifica-se que os coeficientes angulares das variáveis RTRANSF, RPC e CCT são significativamente diferentes de zero (Prob. < nível de significância de 0,05), fato fundamental para fazerem parte do modelo. Outra informação importante é que nesse modelo a Constante - $C$ aparece individualizada, ou seja, cada cross-sections (Estado) tem seu coeficiente angular. 0 poder explicativo do modelo é de $91,3 \%$ ( $R^{2}$ ajustado 0,91303 ), muito superior ao encontrado no modelo comum. Porém, ao analisarmos a estatística de Durbin-Watson (Prob. 1,27591) percebe-se uma auto-correlação positiva dos resíduos, considerando o número de observações e variáveis do modelo e os valores tabelados, mas isso pode estar sendo influenciado por ocorrências passadas e captadas nos resíduos. Esse problema de auto-correlação será mais bem tratado oportunamente.

Após análise do modelo fixo, faz-se necessário compará-lo com o modelo comum no intuito de identificar qual o modelo mais apropriado para esses dados. Para isso, Silva e Cruz Jr. (2004) sugerem o teste de Chow a seguir. 
Quadro 2 - Teste de CHOW entre os Modelos Comum e Fixo

\begin{tabular}{|c|c|}
\hline $\begin{array}{l}\mathrm{R}^{2} \text { modelo comum - } \mathrm{R} \\
\mathrm{R}^{2} \text { modelo fixo - UR } \\
\mathrm{NT}-\mathrm{n}^{\circ} \text { de observações totais } \\
\mathrm{N}-\mathrm{n}^{\circ} \text { de cross-sections } \\
\mathrm{K}-\mathrm{n}^{\circ} \text { de coeficientes da regressão menos } 1\end{array}$ & $\begin{array}{c}0,35759 \\
0,92884 \\
155 \\
26 \\
3\end{array}$ \\
\hline \multicolumn{2}{|l|}{$\left(\mathrm{R}^{2} \mathrm{UR}-\mathrm{R}_{\mathrm{R}}^{2}\right) /(\mathrm{N}-1)$} \\
\hline $\begin{array}{c}\mathbf{F}=\quad \mathbf{4 0 , 4 5 9 5} \\
\text { Valor Tabela } \mathrm{F}=\sim 1,60\end{array}$ & \\
\hline
\end{tabular}

Fonte: Elaborado pelos autores.

O teste de Chow, descrito no Quadro 2, permite selecionar o modelo mais apropriado e pode ser construído utilizando-se o $R^{2}$ restrito (modelo comum) e $R^{2}$ não restrito (modelo fixo), com os respectivos graus de liberdade. Considerando a fórmula de Chow descrita acima, encontrou-se o resultado $40,4595>0$ valor tabelado de $F=\sim 1,60$, assim sendo, não aceita a hipótese nula de que os interceptos são comuns e o modelo mais apropriado é o fixo. 0 próximo passo é estimar o modelo de efeitos aleatórios, para então saber qual é o mais apropriado.

\subsection{MODELO DE EFEITOS ALEATÓRIOS}

O "Modelo Aleatório" leva em conta o fato de que o termo de erro pode apresentar correlação ao longo do tempo e ao longo das unidades em corte transversal. Segundo Gujarati (2006), pode ser representado pela seguinte função.

$$
Y_{i t}=B_{1}+\sum_{k=2}^{k} B_{k} x_{k i t}+v_{i t} \quad \text { (função 3) }
$$

Onde, $\quad 0 \quad B_{1}$ representa 0 intercepto populacional médio $e \quad 0 \quad \mathbf{v}_{\text {it }}$ é 0 e (erro individual - elemento do corte transversal) mais $\boldsymbol{\mu}_{\mathbf{i}}$ (erro global - elemento combinado da série temporal e do corte transversal).

Este modelo tem como método de estimação os mínimos quadrados generalizados - MQG, que leva em consideração a correlação temporal entre as perturbações (erros) do mesmo indivíduo. É definido como a média ponderada do estimador MQO. Os resultados da estimação do modelo de efeitos aleatórios estão descritos na Tabela 3, a seguir. 
Tabela 3 - Resultado do Painel pelo Modelo Aleatório

\begin{tabular}{|c|c|c|c|c|}
\hline \multicolumn{5}{|c|}{$\begin{array}{l}\text { Variável Dependente: Grau de Endividamento dos Estados - GEE } \\
\text { Método: Pooled Least Squares } \\
\text { Período: } 20002005 \\
\text { Observações Incluídas: } 6 \\
\text { Número de cross-sections usado: } 26 \\
\text { Total de observações do painel: } 155 \\
\text { White Heteroskedasticity-Consistent Standard Errors \& Covariance }\end{array}$} \\
\hline Variáveis & Coeficientes & Erro padrão & Estatística t & Prob. \\
\hline C-Constante & 2,02515 & 0,17580 & 1,15199 & 0,0000 \\
\hline RTRANSF? & $-1,41594$ & 0,26955 & $-5,25292$ & 0,0000 \\
\hline RPC? & $-0,00038$ & 0,00009 & $-4,25167$ & 0,0000 \\
\hline ССТ? & $-0,15986$ & 0,04190 & $-3,81509$ & 0,0002 \\
\hline \multicolumn{5}{|l|}{ Efeitos Aleatório } \\
\hline _AC--C & $-0,57493$ & & _PB--C & $-0,12840$ \\
\hline _AL--C & 0,90923 & & _PE--C & $-0,41639$ \\
\hline _AM--C & $-0,68189$ & & _PI--C & 0,23225 \\
\hline _AP--C & $-1,14844$ & & _PR--C & $-0,24590$ \\
\hline _BA--C & 0,07191 & & _RJ--C & 0,57625 \\
\hline _CE--C & $-0,48487$ & & _RN--C & $-0,72133$ \\
\hline _ES--C & $-0,50015$ & & _RO--C & $-0,13138$ \\
\hline _GO--C & 1,07228 & & _RR--C & $-0,82497$ \\
\hline _MA--C & 0,71478 & & _RS--C & 1,26008 \\
\hline _MG--C & 0,65240 & & _SC--C & 0,17899 \\
\hline _MS--C & 1,30491 & & _SE--C & $-0,57943$ \\
\hline _MT--C & 0,36111 & & _SP--C & 0,66291 \\
\hline PA--C & $-0,72830$ & & _TO--C & $-0,87746$ \\
\hline & 0,90883 & \multicolumn{2}{|c|}{ Média da var. dep. } & 1,36424 \\
\hline $\mathrm{R}^{2}$ aiustado & 0,90702 & \multicolumn{2}{|c|}{ Desvio-padrão da var. dep. } & 0,81436 \\
\hline S.E. da regressão & 0,24832 & \multicolumn{2}{|c|}{$\begin{array}{l}\text { Soma do quad. dos resid. } \\
\text { Estatística de Durbin-Watson }\end{array}$} & $\begin{array}{l}9,31127 \\
1,02806\end{array}$ \\
\hline
\end{tabular}

Fonte: Elaboração própria a partir dos dados da STN/FINBRA.

Analisando os resultados da Tabela 3 percebe-se que os coeficientes angulares de todas as variáveis são significativamente diferentes de zero, que o $R^{2}$ ajustado é elevado $(0,90702)$ e que o resultado da estatística de Durbin-Watson apresenta auto-correlação positiva dos resíduos.

Esses resultados são similares aos apresentados pelo modelo de efeitos fixos (Tabela 2) e que, conforme Quadro 3, o modelo de efeitos aleatórios é mais apropriado que o modelo de efeito comum, o que nos resta verificar qual modelo é melhor, o de efeitos fixos ou aleatórios. 
Quatro 3 - Teste de CHOW entre os Modelos Comum e Aleatório

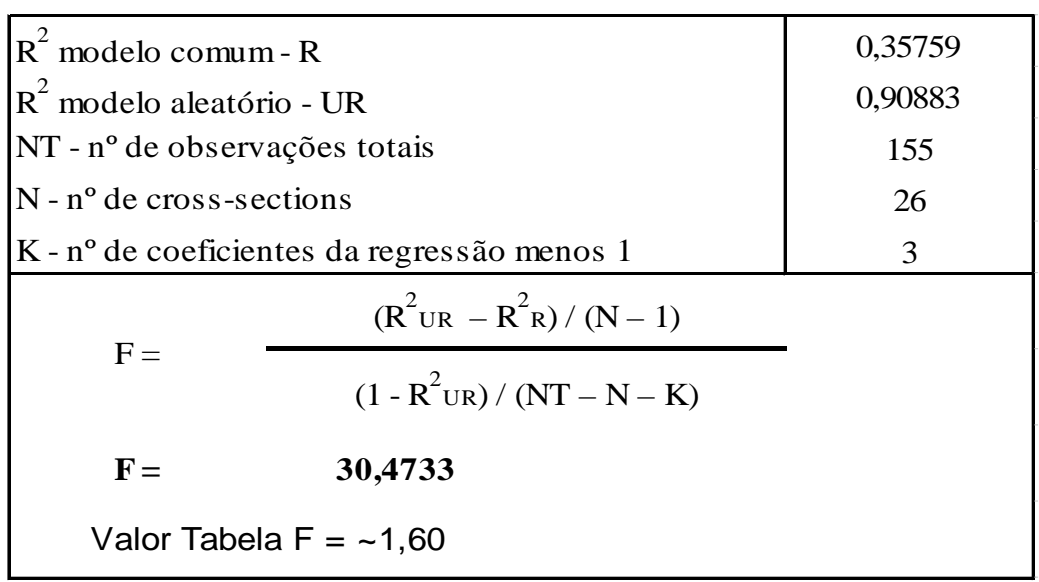

Fonte: Elaborado pelos autores.

De acordo com Gujarati (2006) o teste utilizado para verificar qual modelo é mais apropriado, se de efeitos fixos ou aleatório, é o Hausman, o qual está descrito na Tabela 4.

Tabela 4 - Teste de Hausman

\begin{tabular}{|c|c|c|c|c|}
\hline & \multicolumn{2}{|c|}{ Coeficientes } & \multirow{2}{*}{$\begin{array}{c}\text { (b-B) } \\
\text { Diferença }\end{array}$} & \multirow{2}{*}{$\begin{array}{c}\text { sqrt(diag(V_b-V_B) }) \\
\text { Erro-Padrão }\end{array}$} \\
\hline & (b) Fixo & (B) & & \\
\hline Rtransf & $-1,17293$ & $-1,41540$ & 0,24247 & - \\
\hline RPC & $-0,00040$ & $-0,00038$ & $-0,00002$ & - \\
\hline CCT & $-0,15964$ & $-0,15987$ & 0,00023 & - \\
\hline \multicolumn{4}{|c|}{$\mathrm{b}=$ consistente para $\mathrm{H}_{0}$ e $\mathrm{H}_{1}$} & $\mathrm{~B}=$ inconsistente para $\mathrm{H}_{1}$, eficiente para $\mathrm{H}_{0}$ \\
\hline \multicolumn{5}{|c|}{$\begin{array}{l}\text { Teste: Ho: diferença nos coeficientes não sistemáticos } \\
\text { chi2(4) }=(\mathrm{b}-\mathrm{B})^{\prime}\left[\left(\mathrm{V}_{-} \mathrm{b}-\mathrm{V} \_\mathrm{B}\right)^{\wedge}(-1)\right](\mathrm{b}-\mathrm{B}) \\
=\quad 43.31\end{array}$} \\
\hline $\begin{array}{l}\text { Prob }>\text { chi2 }= \\
(\mathrm{V} \text { b-V B nã }\end{array}$ & $\begin{array}{l}0.0000 \\
\text { é definid }\end{array}$ & sitivo) & & \\
\hline
\end{tabular}

Fonte: Saída STATA ${ }^{\circledR}$ adaptado pelos autores.

Considerando o resultado do Teste de Hausman, onde o Prob $=0,0000<$ nível de significância de 0,05 , pode-se não aceitar a hipótese nula de que os estimadores não diferem substancialmente, e concluir que o modelo mais apropriado é o de efeitos fixos.

Assim sendo, após a realização de todos os testes, conclui-se que o modelo mais apropriado é o de efeitos fixos considerando as variáveis RTRANSF, RPC e CCT, o qual foi estimado novamente e está descrito na Tabela 5. 
Tabela 5 - Resultado Final do Painel pelo Modelo Fixo

Variável Dependente: Grau de Endividamento dos Estados - GEE

Método: Pooled Least Squares

Período: 20002005

Observações Incluídas: 6

Número de cross-sections usado: 26

Total de observações do painel: 129

White Heteroskedasticity-Consistent Standard Errors \& Covariance

\begin{tabular}{|c|c|c|c|c|}
\hline Variáveis & Coeficientes & Erro padrão & Estatística t & Prob. \\
\hline RTRANSF? & $-1,20176$ & 0,23890 & $-5,03048$ & 0,0000 \\
\hline RPC? & $-0,00046$ & 0,00011 & $-4,29781$ & 0,0000 \\
\hline ССТ? & $-0,17058$ & 0,03089 & $-5,52159$ & 0,0000 \\
\hline $\operatorname{AR}(1)$ & 0,31023 & 0,08978 & 3,45551 & 0,0008 \\
\hline \multicolumn{5}{|l|}{ Efeitos Fixos } \\
\hline _AC--C & 1,28085 & & _PB--C & 1,71322 \\
\hline _AL--C & 2,97910 & & _PE--C & 1,67474 \\
\hline _AM--C & 1,23793 & & _PI--C & 2,11784 \\
\hline _AP--C & 0,77100 & & _PR--C & 1,90488 \\
\hline _BA--C & 2,03965 & & _RJ--C & 2,74176 \\
\hline _CE--C & 1,52984 & & _RN--C & 1,19431 \\
\hline _ES--C & 1,54277 & & _RO--C & 1,88142 \\
\hline _GO--C & 2,94523 & & _RR--C & 1,04606 \\
\hline _MA--C & 2,50763 & & _RS--C & 3,39644 \\
\hline _MG-C & 3,00511 & & _SC--C & 2,21938 \\
\hline _MS--C & 3,29533 & & _SE--C & 1,33754 \\
\hline _MT--C & 2,16530 & & _SP--C & 2,87704 \\
\hline PA--C & 1,21904 & & =TO--C & 1,06789 \\
\hline $\mathrm{R}^{2}$ & 0,95196 & \multicolumn{2}{|c|}{ Média da var. dep. } & 1,34182 \\
\hline $\mathrm{R}^{2}$ aiustado & 0,93789 & \multicolumn{2}{|c|}{ Desvio-padrão da var. dep. } & 0,80680 \\
\hline S.E. da regressão & 0,20107 & \multirow{2}{*}{\multicolumn{2}{|c|}{$\begin{array}{l}\text { Soma do quad. dos resid. } \\
\text { Estatística de Durbin-Watson }\end{array}$}} & 4,00246 \\
\hline Estatística F & 653,94747 & & & 2,07229 \\
\hline Prob(Estatística F) & 0,00000 & & & \\
\hline
\end{tabular}

Fonte: Elaboração própria a partir dos dados da STN/FINBRA.

0 modelo de efeitos fixos foi estimado considerando um termo auto-regressivo (AR) com uma defasagem para resolver o problema de auto-correlação nos resíduos (estatística de Durbin-Watson 2,07229 - está na área de ausência de auto-correlação). A inclusão do AR(1) foi suficiente para corrigir a auto-correlação e sua aceitação nos mostra que o endividamento em t-1 impacta o endividamento em t.

Com a inclusão do $A R(1)$, além de resolver o problema de auto-correlação, o poder explicativo do modelo melhorou $\left(R^{2}=93,8 \%\right)$, os coeficientes angulares das variáveis continuaram sendo diferentes de zero e o modelo como um todo também é significativo.

\section{CONCLUSÃO}

O objetivo deste trabalho foi identificar os fatores que influenciam o endividamento dos Estados Brasileiros, considerando os aspectos relacionados à estrutura de receitas e despesas. 
A técnica estatística utilizada é denominada de dados em painel, a qual demonstrou que o endividamento é influenciado pelas receitas de transferências (RTRANSF), pela receita per capita (RPC) e pela cobertura corrente total (CCT), essa influência ocorre de forma negativa, ou seja, um aumento nessas variáveis diminui o endividamento. Isso confirma a hipótese orientadora do trabalho que os aspectos relacionados à estrutura de receitas influenciam para a redução do endividamento.

É possível observar que o endividamento em t-1 influencia de forma positiva o endividamento em $t$, ou sej a, para prever o endividamento é necessário considerar as receitas de transferências, a receita per capita, a cobertura corrente total e o endividamento de t- 1 . Dessa forma, um aumento nessas receitas em 2004, considerando o endividamento de 2003, influenciou na redução do endividamento em 2005 e/ou amenizou os aumentos.

O impacto dessas variáveis está ligado diretamente ao grau de endividamento dos Estados, onde aqueles Estados com menor endividamento são mais afetados pelos aumentos nessas receitas.

Um fator limitador desta pesquisa é a quantidade de períodos analisados, pois foram considerados apenas 6 anos, isso pode causar algumas distorções.

Como sugestão de novas pesquisas, pode-se verificar se esse resultado se confirma aplicando para os municípios ou futuramente para os próprios estados, mas considerando um número maior de períodos.

\section{REFERÊNCIAS}

BRASIL. Banco Central. Relatório do Banco Central do Brasil. Boletim do Banco Central do Brasil n 38, set/2002. Disponível em <http: //www. bcb.gov.br>. Acesso em 5/04/2007.

. Lei Complementar n 101, de 4 maio de 2000. Estabelece normas de finanças públicas voltadas para a responsabilidade na gestão fiscal e dá outras providências. Disponível em <http://www.planalto.gov.br/CCIVIL/Leis/LCP/Lcp101.htm>. Acesso em 25/02/2008.

Ministério da Fazenda. Tesouro Nacional. Disponível em: <http://www.tesouro. fazenda.gov. br>.

GUJARATI, Damodar. Econometria básica. 4 ed. Traduzido por Maria José Cyhlar Monteiro. Rio de Janeiro: Elsevier, 2006.

LOPREATO, Francisco Luiz. O endividamento dos governos estaduais nos anos 90 . Texto para Discussão. IE/UNICAMP, Campinas, n. 94, mar. 2000.

MARTINS, Gilberto de Andrade. Manual para elaboração de monografias e dissertações. 3 ed. São Paulo: Atlas, 2002.

MELLO, Gilmar Ribeiro de; SLOMSKI, Valmor. Verificando o Endividamento dos Estados Brasileiros: Uma Proposta Utilizando Análise Multivariada de Dados. Anais do 30 EnANPAD, 2006.

MELLO, Gilmar Ribeiro de, et al. Identificando o Endividamento dos Estados Brasileiros: 
uma proposta através de análise discriminante. Enfoque Reflexão Contábil, v. 25, n. 1, p. 05-14, Janeiro-Abril/2006.

MELLO, Gilmar Ribeiro de; SLOMSKI, Valmor; CORRAR, Luiz João. Estudo dos Reflexos da Lei de Responsabilidade Fiscal no Endividamento dos Estados Brasileiros. UnB Contábil, v. 8, n. 1, p. 41-60, Janeiro-Julho/2005.

PEREIRA, César A. Guimarães. O endividamento público na Lei de Responsabilidade Fiscal. Revista Diálogo Jurídico, n. 10, 01/2002. Disponível em: <www.direitopublico.com.br>. Acesso em: 18/04/2006.

RIGOLON, F.; GIAMBIAGI, F. A renegociação das dívidas e o regime fiscal dos estados. Em: GIAMBIAGI, F.; MOREIRA, M.M. (orgs.). A economia brasileira nos anos 90. Rio de Janeiro: BNDS, 1999.

SILVA, Isabela Fonte Boa Rosa; SOUSA, Maria da Conceição Sampaio. Determinantes do endividamento dos Estados Brasileiros: uma análise de dados de painel. Universidade de Brasília/departamento de Economia. Texto 259, 2002.

SILVA, O.M.; CRUZ Jr, JC. Dados em painel: uma análise do modelo estático. In: Santos, M.L; Vieira, W.C. (org). Métodos quantitativos em economia. Viçosa: UFV, 2004.

VERSIANI, Flávio Rabelo. A dívida pública interna e sua trajetória recente. Universidade de Brasília/departamento de Economia. Texto 284, março/2003.

WOOLDRIDGE, Jeffrey. Introdução à econometria. Traduzido por Rogério César de Souza e José Antônio Ferreira. São Paulo: Thomson, 2006.

\section{ENDEREÇO DOS AUTORES}

Universidade Estadual do Oeste do Paraná, Centro de Ciências Sociais Aplicadas, Campus de Francisco Beltrão.

Rua Maringa, 1200

Vila Nova

85600-000 - Francisco Beltrao, PR - Brasil

Faculdade de Economia, Administração e Contabilidade

Universidade de São Paulo

Avenida Professor Luciano Gualberto, 908 - Cidade Universitária

Sao Paulo, SP - Brasil

05508-900 